\title{
Evaluation of the durability of asphalt concrete on polymer modified bitumen
}

\author{
Artur Onishchenko ${ }^{1, *}$, Larysa Stolyarova ${ }^{1}$, Andrii Bieliatynskyi ${ }^{2}$ and Natalia Samosudova ${ }^{3}$ \\ ${ }^{1}$ National Transport University, Kiev, Ukraine \\ ${ }^{2}$ National Aviation University, Kiev, Ukraine \\ ${ }^{3}$ Moscow State University of Civil Engineering, 26, Yaroslavskoeshosse, Moscow, 129337, \\ Russia
}

\section{Introduction}

It is known that use of conventional decisions in the road building to enhance the road concrete mixes quality due to improvement of their composition selection and the upgrading the preparation process doesn't eliminate in full the problem of the highways asphalt covering strength and durability enhancement.

The recent research results show that one of the most promising ways to increase the asphalt concrete durability is the thermoplastic and thermoplastic elastic polymers as the bitumen and road concrete mix modifiers [1-10]. One of such modifiers is the BASF Butanol NS 198 cationic latex which according to American scientists research results improves the bitumen heat resistance, elasticity and adhesive properties. Taking into account that the climatic conditions and the paving bitumen used in Ukraine are different from those in the western countries and in the USA, it emerged necessity to study influence of these modifying agents to enhance the asphalt concrete layers service life taking into consideration the conditions in Ukraine and the domestic road building materials properties.

Possibility to apply the Butanol NS 198 modifying agent in Ukraine is studied since 2002. The Derzhdor research institute and KNARU research teams investigated the influence of this modifier on the paving bitumen and asphalt concrete properties $[2,8]$. The laboratory test results have confirmed the possibility of the paving bitumen properties improvement using the Butanol NS 198 modifier. Such bituminous polymers demonstrate the certain dependence of a binding agent strengthening and the increasing elasticity appearance upon the polymer amount increase. Sensitivity to a temperature lowering decreases. These facts create the preconditions for asphalt concrete strength and resistance increase as well as its shift resistance and crack growth resistance in the road covering.

However, the influence of this modifying agent on the asphalt concrete properties and especially on its behavior in the road structure was studied insufficiently. Therefore, the following questions are considered in given work:

- designing the optimal compositions of asphalt concrete with bitumen modified with the Butanol NS 198 cationic latex;

- determining the designed thermo-rheological characteristics of asphalt concrete with the modified bitumen;

\footnotetext{
* Corresponding author: artur onish@bigmir.net
} 
- analysis of the Butanol NS 198 modifier influence on the pavement on the base of the asphalt covering crack growth resistance dependence on the transport traffic intensity.

\section{Materials for research}

For research conduction to prepare the modified bitumen and the polymer asphalt concrete there were used the stone materials from the Malynsky enterprise and the mineral powdered lime, the petroleum paving bitumen of 60/90 grade from the Mozyrsky enterprise, and the Butanol NS 198 modifier. The components quantity determination results showed their compliance with the asphalt concrete functional standard [11]. To obtain the uniform asphalt concrete samples and to ensure the same specific surface of the mineral components the stone material previously was dispersed on the standard fractions. While selecting the asphalt concrete composition the standard requirements to its physic-mechanical characteristics were observed.

During research there was used the most widely applied for the covering arrangement DSTU Б B.2.7-119 asphalt concrete of such grain composition: macadam of 5-10 fraction $40 \%$; crashed sand $-52 \%$; mineral powder $-8 \%$. For comparison the road concrete mixes were prepared using the petroleum paving bitumen 60/90 with the latex addition into mixture during its mixing. At preparation of the bitumen modified with polymer there have being checked both the binding agent properties and its producing processibility. It allowed determining the inadmissible process modes of the modified bitumen preparation and the optimal and rational conditions of its preparation and use.

\section{Asphalt concrete samples preparation procedure}

To prepare the asphalt concrete samples there was used standard and special equipment of the "Transport construction materials and designs" prof. G.K. Sunya laboratory under the road building materials and chemistry chair of the National transport university. The beam samples were prepared on the sector press (fig. 1) of Radovsky-Scherbakov design [12] that creates the asphalt concrete consolidation conditions with the light, middle and heavy rolls.

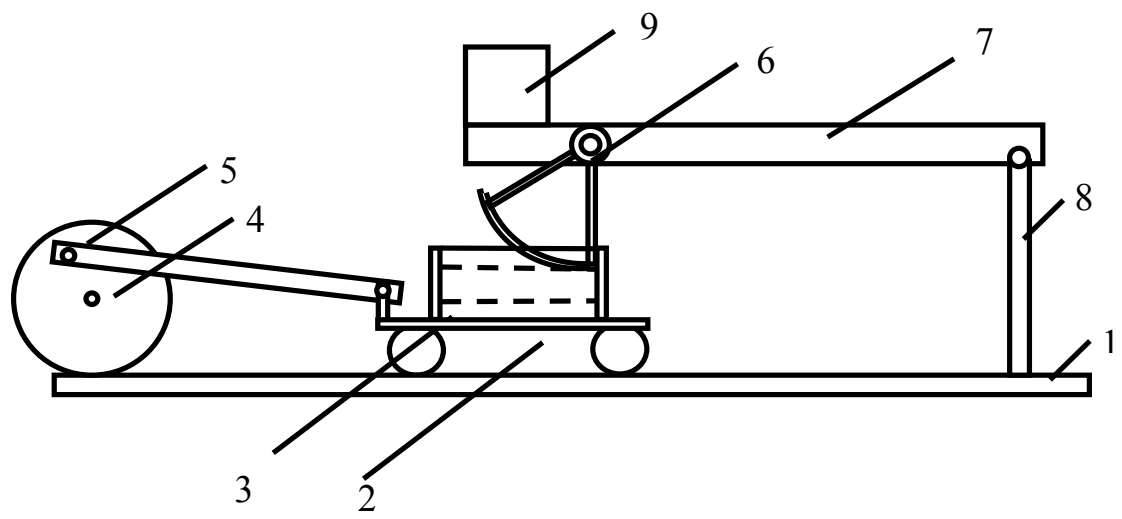

1 - bed; 2 - cart; 3 - mould; 4 - electric motor with reduction gear and flywheel; 5 - connecting-rod and crank gear; 6 - sector; 7 - lever; 8 - stand; 9 - weight.

Fig. 1. Sector press of Radovsky-Scherbakov design to produce the asphalt concrete beam samples.

Sector press consists of the bed 1 along which the cart with the installed on it mould 3 moves. The cart is driven by the electric motor 4; the mixture consolidation in the mould is performed by sector. 
On the sector press it was used the optimal process of the selected compositions consolidation to obtain the minimum consolidation factor 0.98 .

\section{Asphalt concrete testing procedure}

The asphalt concrete physical-mechanical and designed characteristics were determined according to functional regulations $[12,14,15]$.

To determine the tensile strength limits at bending the samples were tested for bend with concentrated force according to statically established scheme as the beam on two supports. The tests were carried out on the МИП-500 machine at temperature of $0{ }^{\circ} \mathrm{C}$ and deformation rate $100 \mathrm{~mm} / \mathrm{min}$. Before testing the samples were subjected to thermostating during 8-10 hours in the heat chamber. Then the samples were transferred in heat insulation to the testing machine supports. While testing the maximum destructive load $P$ was recorded and the tensile strength limits at bending were determined by means of formula

$$
R_{3 \odot U H}=\frac{3}{2} \cdot \frac{P l}{b h^{2}}
$$

where $P$ is the maximum destructive load at bending; $l$ is distance between the supports; $b$ is the sample width; $h$ is the sample height.

The asphalt concrete samples modulus of elasticity was determined at temperature of 0 ${ }^{\circ} \mathrm{C}$ and the load action duration of $0.1 \mathrm{~s}$ employing the pendulum device of RadovskyScherbakov design (fig. 2).

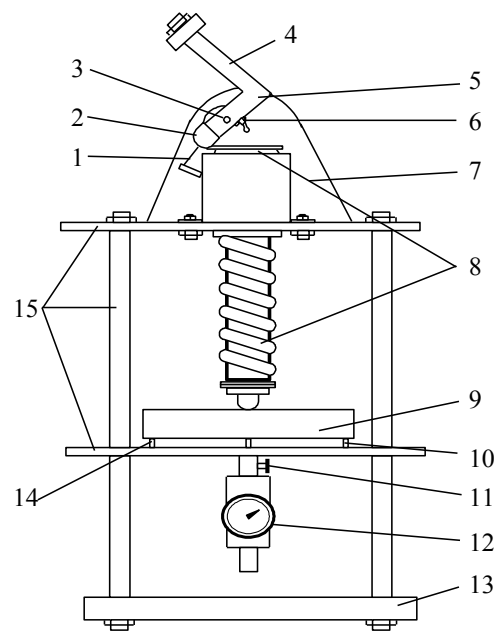

1 - load transmission gear, 2 - adjustment nut, 3 - axle, 4 - pendulum in the lever form, 5 - threaded roller, 6 nut, 7 - bracket, loading mechanism, 9 - beam sample, 10 - mobile support, 11 - indicator, 12 - deal indicator, 13 - bed, 14 - immobile support, 15 - frame made of the steel bars.

Fig. 2. Pendulum device.

Before testing the samples were subjected to the previous thermostating at the operating temperature. Prepared for testing sample was placed on the supports and loaded with the help of the loading system which ensures the specified loading level in the sample at designed time of its action of $0.1 \mathrm{~s}$. During this procedure the rebound deflection was measured. The modulus of elasticity was calculated with the help of formula

$$
E=P l^{3} /(48 f J) \text {, }
$$


where $P$ is the vertical loading; $f$ is the rebound deflection; $J$ is the sample cross-section inertia moment.

To determine the fatigue factor it was used the procedure based on the different stress levels applying with measurement of time till destruction. There were tested the samples for determination of the continuous creep under the uniaxial tension conditions at temperature of $0{ }^{\circ} \mathrm{C}$ according to procedure [16] and using the installation shown in fig. 3 .

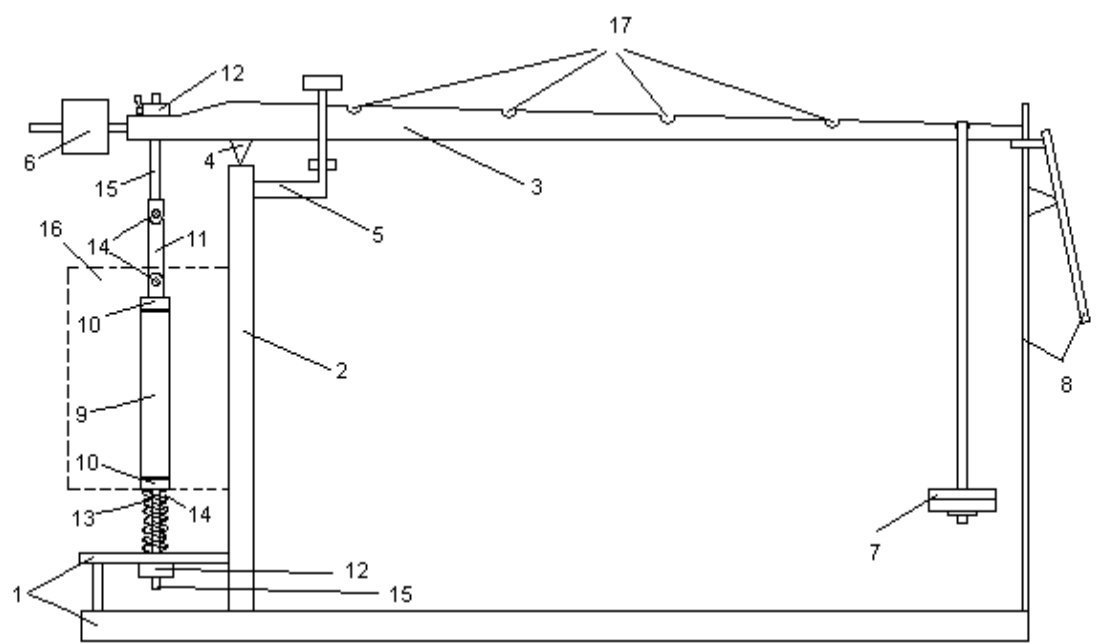

1 - base; 2 - stand; 3 - balancing lever; 4 - prism; -5 - restrictor; 6 - balance weight; 7 - suspension with the balance weights; 8 - loading device; 9 - sample; 10 - gripping devices; 11 - cross-over link; 12 - nuts; 13 - spring; 14 - pivot; 15 - tension bolts; 16 - heat-chamber; 17 - sockets for suspension.

Fig. 3. Diagram of installation A-1 to test the samples durability.

During testing it was recorded time till destruction at different stress levels and the fatigue parameters were determined using the following formula:

$$
m=\lg \frac{t_{p}\left(\sigma_{1}\right)}{t_{p}\left(\sigma_{2}\right)} \cdot\left(\lg \frac{\sigma_{2}}{\sigma_{2}}\right)^{-1}
$$

where $\sigma_{l}, \sigma_{2}$ are the stresses in the sample, $t_{p}\left(\sigma_{1}\right), t_{p}\left(\sigma_{2}\right)$ is the time till the sample destruction.

\section{Research results analysis}

Research results of the Butanol NS 198 polymer influence on the studied bitumen properties have shown that the modifying agent amount equals about 2-4\% of the bitumen mass. Such amount of the polymer ensures the highest physical-mechanical properties of asphalt concrete. In case of the modifier direct introducing into prepared road concrete mix its rational amount was equal to 3-4 \% of the bitumen mass. To provide correct equalization of the asphalt concrete researched compositions physical-mechanical properties in this work there are shown the results of the modifier use in amount of $4 \%$ of the bitumen mass.

The results of the asphalt concrete physical-mechanical properties determination depending on the binding agent amount are the following.

In case of the binding agent from $5.4 \%$ to $6 \%$ relative to $100 \%$ of the mineral part the average density values virtually did not change, and the water saturation factor uniformly decreased at the bitumen amount increase (fig. 4-5) both for polymer asphalt concrete (PAC) and for the conventional asphalt concrete. 

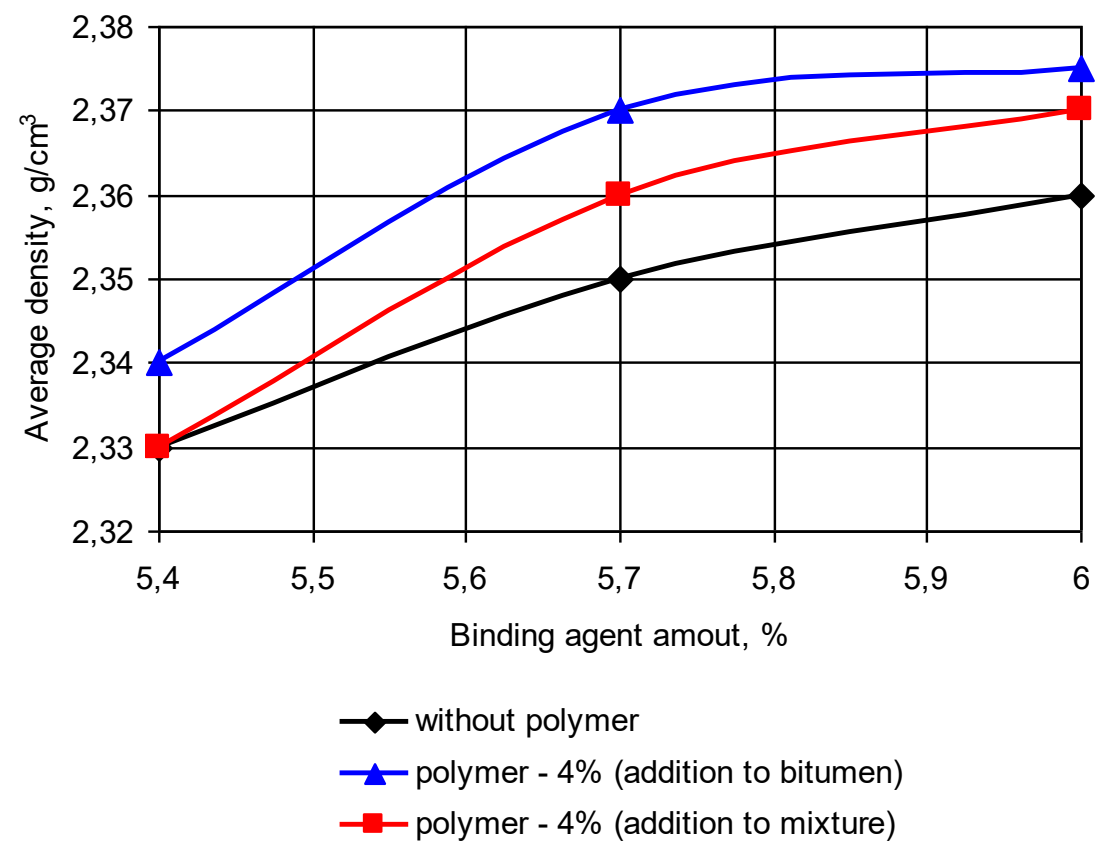

Fig. 4. Dependence of the asphalt concrete average density upon the binding agent amount.
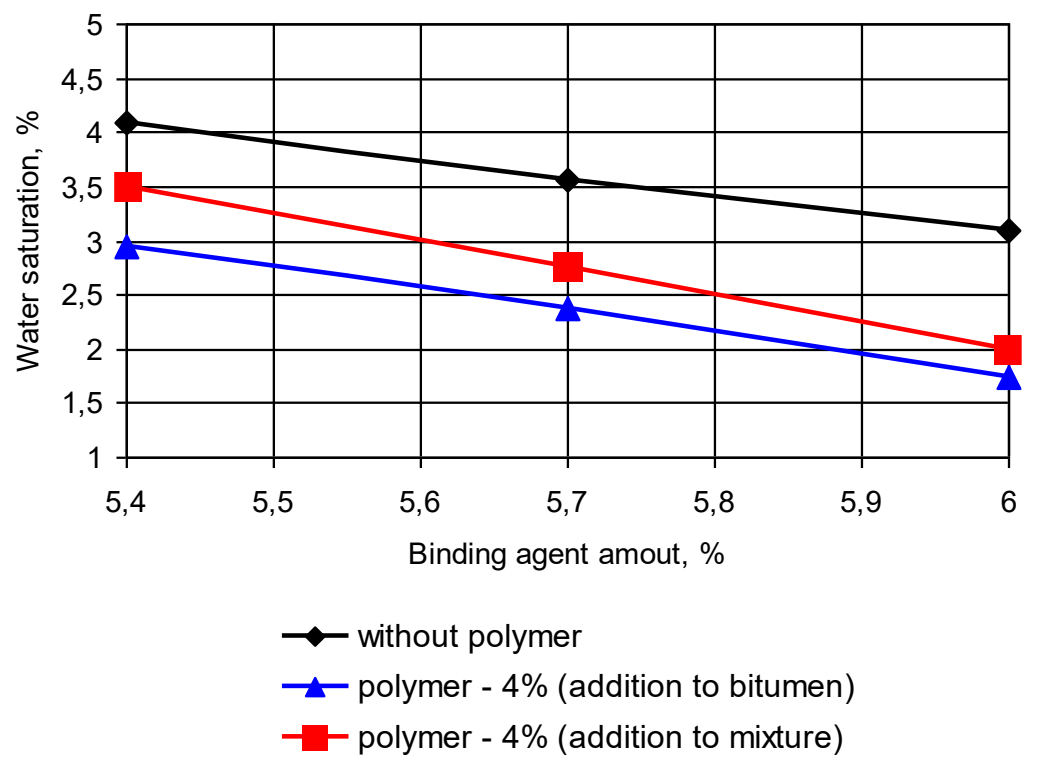

Fig. 5. Dependence of the asphalt concrete water saturation upon the binding agent amount.

The water saturation factor decrease by 1.5-2 times in the polymer asphalt concrete (PAC) demonstrates improvement of its water resistance as compared with conventional asphalt concrete, and additionally it is possible to say about the improvement of asphalt concrete general longevity in covering at the water-freeze factors influence. At that the 
water saturation factor decrease rate is virtually the same both for conventional asphalt concrete and for PAC.

The strength factors determination results are shown in fig. 6-9 and indicate the polymer asphalt concrete advantages in comparison with the conventional asphalt concrete both at the rational amount of the binding agent and at other amounts.
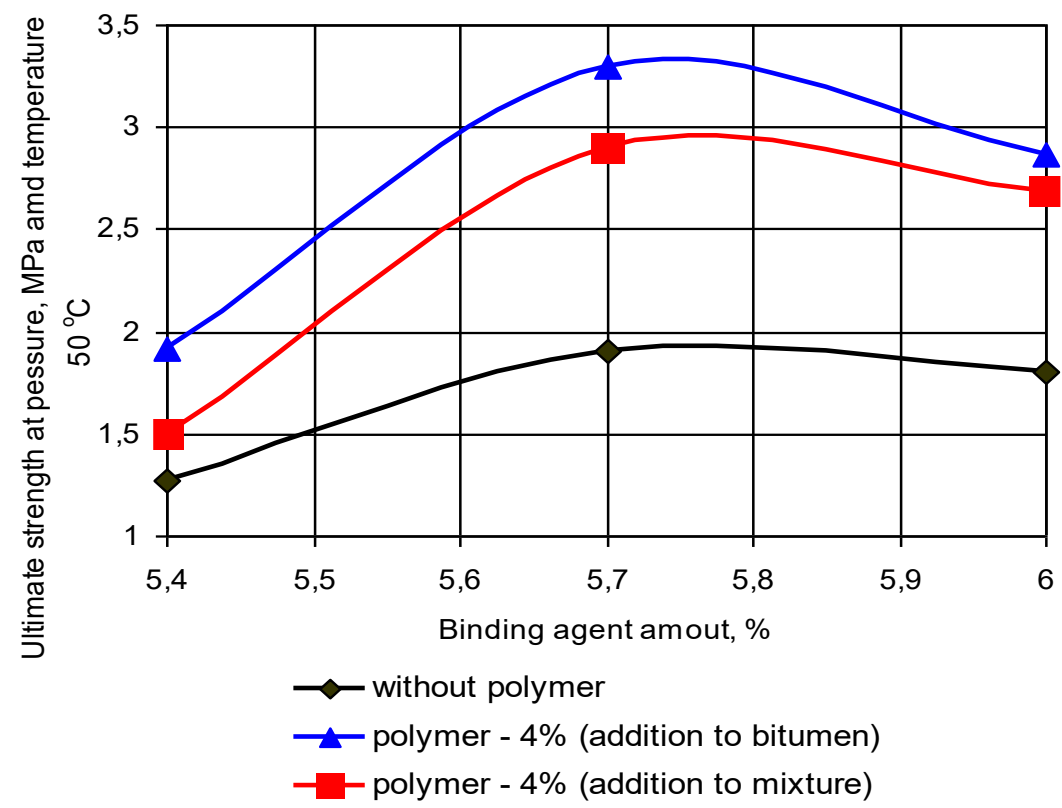

Fig. 6. Dependence of the asphalt concrete ultimate strength at temperature of $50 \mathrm{oC}$ during pressure upon the binding agent amount.

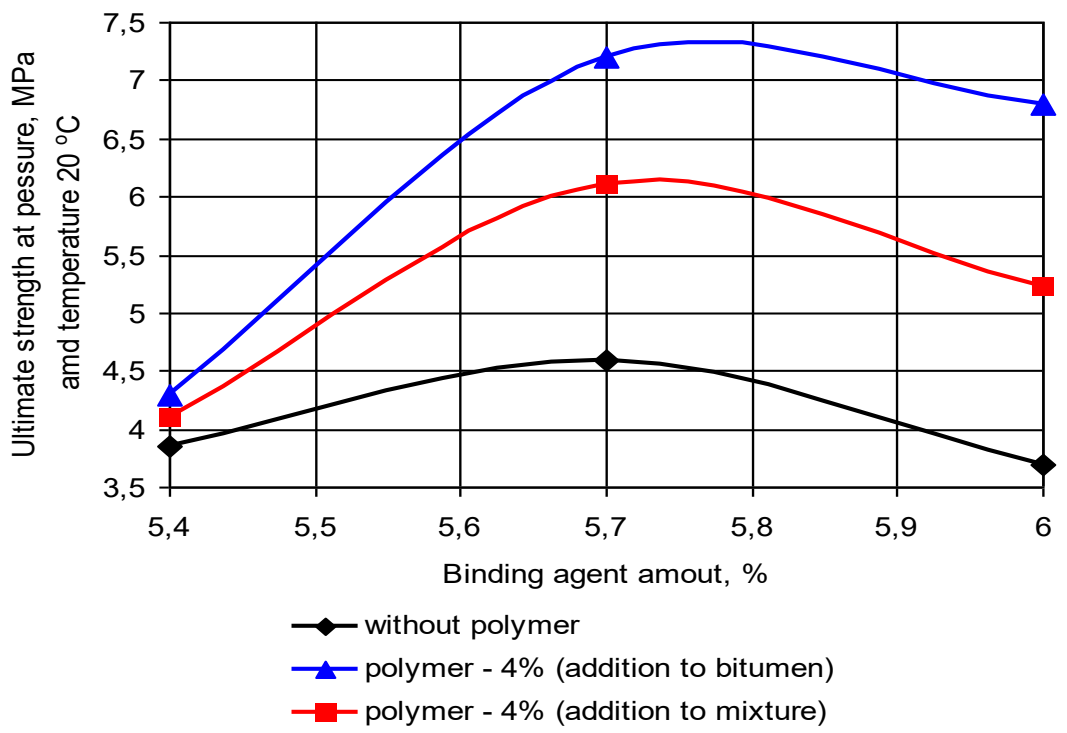

Fig. 7. Dependence of the asphalt concrete ultimate strength at temperature of $20^{\circ} \mathrm{C}$ during pressure upon the binding agent amount. 


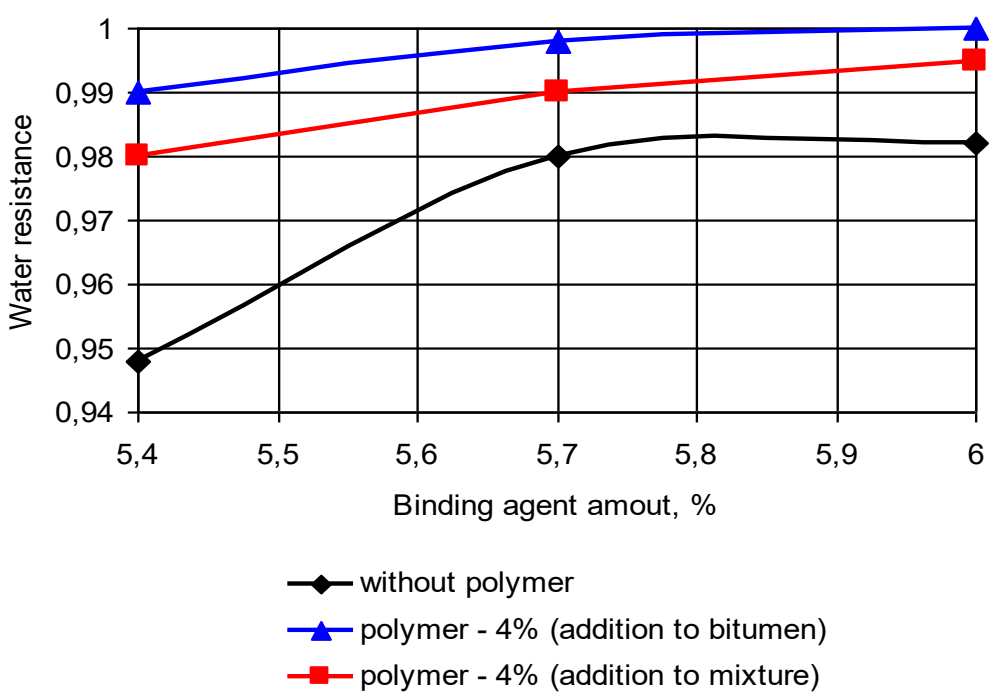

Fig. 8. Dependence of the water resistance upon the binding agent amount.

For example, the main parameters of the physical-mechanical properties PAC $\mathrm{R}_{50}$ - by 1.5-1.9 times greater than for conventional asphalt concrete (fig. 6), $\mathrm{R}_{20}-$ by 1.2-1.7 tines (fig. 7), the wayer resistance factor is greater by $5-10 \%$ (fig. 8), the continuous water resistance factor is greater by $10-20 \%$ (fig. 9).

The standard physical-mechanical parameters study results confirmed the results of other scientists concerning the positive influence of this modifying agent on the PAC properties improvement. However, it is necessary to note that these parameters nay be used mainly for estimation of the asphalt concrete properties as material.

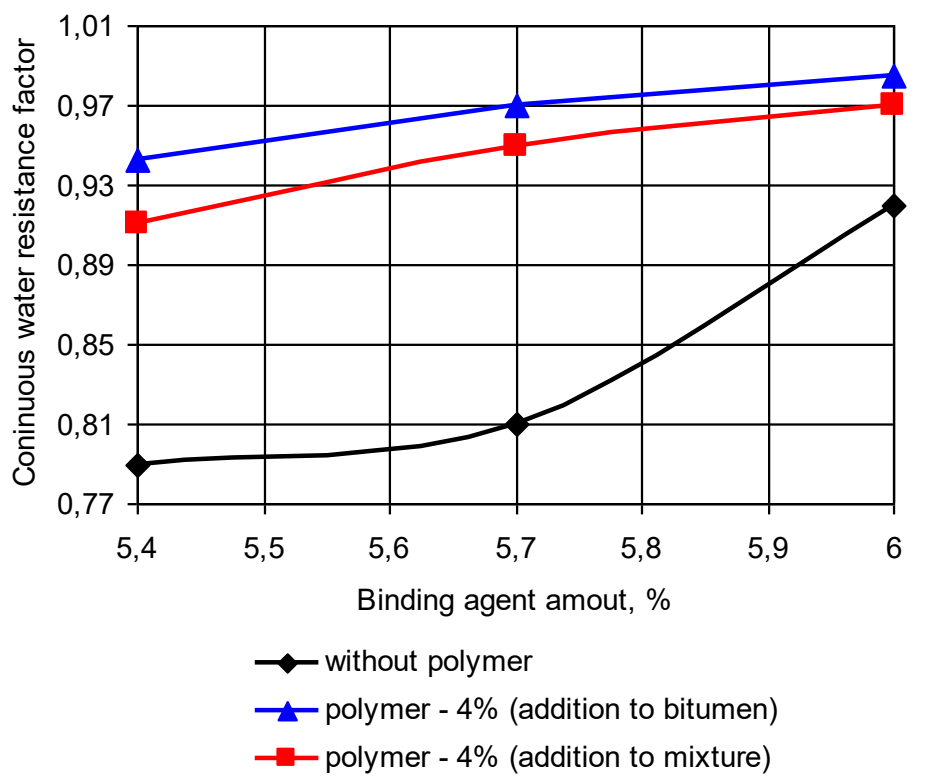

Fig. 9. Dependence of continuous water resistance factor upon the binding agent amount. 
To provide the complete estimation of any modifiers, including the Butanol NS 198, influence on the asphalt concrete durability in paving it is necessary and sufficiently to determine its design characteristics with further execution of corresponding calculations. They itself allow estimating deflected mode of the paving structure and determining number of parameters which allow determining expediency of its use from point of view of ensuring and improving the paving durability. To such parameters there can be referred, for example, number of the vehicles passages till destruction, the paving thickness decrease while ensuring the sane durability, decrease of the repairs frequency, etc.

Results of the asphalt concrete tensile strength at bending determination are shown in table 1. They indicate the PAC tensile strength increase as compared to conventional asphalt concrete and show the bitumen polymer advantages against the paving bitumen (approximately by 1.2 times). The durability function parameters in table 1 also confirmed the considerable benefit of polymer asphalt concrete (approximately by 1.3 times), and this characteristic shows that the PAC use significantly increases the asphalt covering both durability and strength, and additionally it is possible to predict that it will increase the resistance to action of destructive factors such as transport and temperature loadings. The design modulus of elasticity determination results (table 1) showed that this parameter is virtually the same for studied materials, i.e. at low temperatures it has the sufficient deformability and resistance to the temperature cracks appearance.

Table 1. Results of the asphalt concrete design characteristics determination.

\begin{tabular}{|c|c|c|c|}
\hline Asphalt concrete type & $\begin{array}{c}\text { Tension strength } \\
\text { at bending, } R_{\text {bend }}, \\
\mathrm{MPa}\end{array}$ & $\begin{array}{c}\text { Durability } \\
\text { function } \\
\text { parameter, } \\
m\end{array}$ & $\begin{array}{c}\text { Modulus of } \\
\text { elasticity, } \\
E, \mathrm{MPa}\end{array}$ \\
\hline Asphalt concrete & 9.9 & 5.2 & 6780 \\
\hline PAC & 12.1 & 6.7 & 6650 \\
\hline
\end{tabular}

On basis of determined design characteristics to evaluate the durability there were carried out the comparing calculations of paving two constructions according to existing procedure (fig. 10).

a)

Fine bituminous concrete, type B, grade I, dense, 60/90

Coarse-graine asphalt concrete, type B, grade I, porous, 60/90-

Black macada -

Middle sand -

Road bed soil - sandy loam

b)

Fine bituminous concrete, type B,

I grade, dense, on bitumen 60/90,

modified with Butanal NS 198 -

Coarse-graine asphalt concrete, type B, grade I, porous, $60 / 90-10 \mathrm{~cm}$

Black macada -

Middle sand

Road bed soil - sandy loam

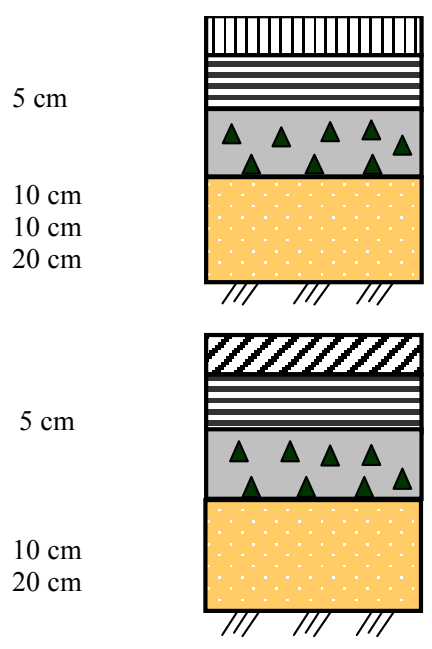

a) using asphalt concrete; b) using PAC.

Fig. 10. Paving structure. 
The asphalt concrete and PAC design characteristics were determined in experimental way according to specifies procedures. The asphalt concrete and PAC compositions were the same as during the previous research.

The calculation results analysis confirmed the previous investigations with respect to asphalt concrete covering durability extension. In this case at loading of $60 \mathrm{kN}$ the paving durability at PAC application by 3.6 times greater than at the conventional asphalt concrete application, at loading of $100 \mathrm{kN}$ - by 3.3 times, and at loading of $15 \mathrm{kN}$ - by 3.0 times (fig. 11).

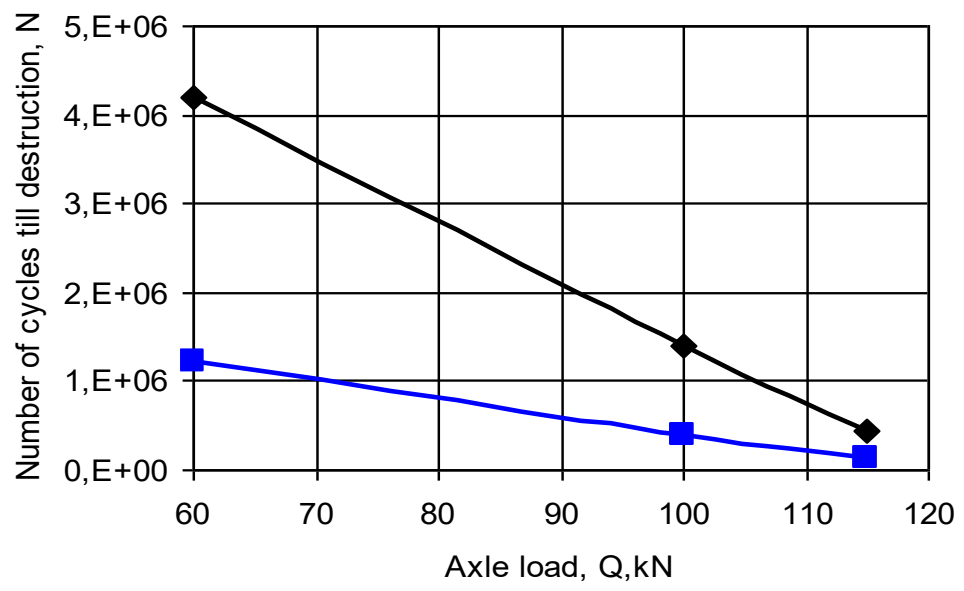

$\neg$ with modifier $\rightarrow-$ without modifier

Fig. 11. Dependence of asphalt concrete durability upon the axle load.

\section{Conclusion}

1. Conducted research showed that the asphalt concretes produced using the Butonal NS 198 meet the requirements to hot asphalt concrete and have higher strength and durability parameters.

2. The polymer asphalt concrete design characteristics values change in sufficiently wide range depending on the binding agent amount shows the possibility of active regulation of its properties under the designing actual conditions.

3. Higher water resistance and extended durability of these PACs ensure the preconditions of their use in different regions of Ukraine.

4. Research results show that to get the maximum effect from the modifying agent application it is desirable to perform the scientist support during its field use and also the operational conditions monitoring to collect statistic data and carry out the necessary corrections to obtain the best results.

\section{References}

1. W. Trakarnpruk, R. Chanathup, Journal of Metals, Materials and Minerals 15(2), 79-87 (2005) 
2. A. Onishchenko, M. Kuzminets, S. Aksenov, An international journal on operation of farm and agri-food industry machinery. Motrol. Commission of motorization and energetic in agriculture 8, 101-106 (2014)

3. L.M. Gokhman, E.M. Gurariy, A.R. Davydova, K.I. Davydova, Polymer - bitumen binders based on SBS for road construction (Informavtodor, Moscow, 2002)

4. A.M. Onishchenko, V.V. Mozgoviy, V.F. Nevinglovsky, Former Soviet Union Area Workshop on Pavement Technologies 2010 Xi'an China, 1-9 (2010)

5. V.A. Zolotarev, Avtoshlyahovik Ukraine 3, 29-31 (2003)

6. G.N. King, B.S. Radovsky, News in the road business. Scientific and technical information collection 6, 1-28 (2004)

7. G.N. King, B.S. Radovsky, News in the road business. Scientific and technical information collection 6, 28-62 (2004)

8. V.O. Zolotaryov, S.G. Galkin, S.V. Kishchinsky, News of the Donbass State Academy of Architecture and Architecture. Composition materials for work 1(43), 16-23 (2004)

9. A.M. Onishchenko, M.P. Kuzminets, V.P. Redchenko, D.Y. Tarnopolsky, S.Yu. Axionov, Theoretical and experimental design of the Pivdenny bridge across the river. Dnipro in metro Kyiv: monograph (NTU, Kiev, 2014)

10. N.Z. Habib, I. Kamaruddin, M. Napiah, I.M. Tan, Proceeding of MUTRFC2010, 79-87 (2010)

11. G. Polacco, S. Berlincioni, D. Biondi, J. Stastna, L. Zanzotto, European Polymer Journal 41, 2831-2844 (2005)

12. DSTU B.V.2.7-119-2011 Sumy asphalt concrete and asphalt concrete road and aerodrome. Technological mind.

13. V.V. Mozgovy, A.M. Onishchenko, O.M. Kutsman, V.F. Nevnglovsky, M.V. Garkusha, S.Yu. Aksionov, Budding materials, virobi and sanitary technology 43, 201205 (2012)

14. DSTU B B.2.7-319: 2016 Mixtures of asphalt and asphalt concrete road and airfield. Test methods.

15. A.M. Onishchenko, M.P. Kuzminets, V.F. Nevinglovsky, M.V. Garkusha, Theoretical and practical studies of the asphalt concrete pavement resource on reinforced concrete transport structures: monograph (NTU, Kiev, 2015)

16. A.M. Onishchenko, V.V. Stozhka, O.M. Leshchuk, 17th International Conference on Geoinformatics - Theoretical and Applied Aspects (2018) 